\title{
Effect of natural extracts on the stability of sunflower oil and acrylamide formation at different thermal treatments
}

\author{
El-Naggar E.A.* \\ Food Science and Technology Department, Faculty of Agriculture, Al-Azhar University, Assiut, Egypt
}

\begin{abstract}
This study was conducted to reduce the simulated chemical changes of sunflower oil during intermittent heating and / or frying model technique, and to improve the thermal stability of oil, and to study the effects on acrylamide formation level by some additives such as

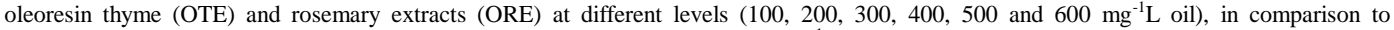
standard oil sample (without addition of extracts) and / or (with addition $200 \mathrm{mg}^{-1} \mathrm{~L}$ oil of BHA), and the chemical changes were correlated with acrylamide content aiming at establishing prediction models for estimating acrylamide content; during intermittent heating and / or frying model technique of potato chips at $175^{\circ} \mathrm{C}$ for $24 \mathrm{hrs}$. at three consecutive days ( 8 hrs. daily). The results could be concluded that addition of OTE and/ or ORE to sunflower oil kept its characteristics from being deteriorated. During the simulated heating and / or frying model technique, the OTE or ORE act as an antioxidant taking part in the chain radical oxidation, as well as simultaneously inhibiting the thermal processes occurring in oil. Induction period (IP) was decreasedby increasing the thermal treatment period. Moreover, the addition of OTE and/ or ORE up to $400 \mathrm{mg}^{-1} \mathrm{~L}$ oil increase IP before thermal treatment then slows down the decreasing of the IP in comparison to the control samples, and TPCs, TBA and acrylamide content of control oil samples were significantly lower than that of the oil samples treated with OTE and/or ORE.Under the conditions simulated heating and / or frying model technique, the OTE inhibits oxidative processes more strongly than ORE or BHA. The results demonstrate that the heating model technique causes a slower increase in acrylamide content during treatment at $175^{\circ} \mathrm{C}$ in comparison to frying model technique, $(39.18 \%)$ under heating model technique. While, ORE reduced the acrylamide ranged by $25.54 \%$ and $27.48 \%$ fewer than $500 \mathrm{mg}^{-1} \mathrm{~L}$ oil during frying and heating model technique respectively. The correlation coefficient between acrylamide level and frying time was very high $(\mathrm{r}=0.986)$ for control sample, and an equation for prediction the acrylamide was $\gamma=$ $-190.9+0.116 \mathrm{X}$. The correlation coefficient between acrylamide level and TPCs content was very high $(\mathrm{r}=0.994)$ for control sample, while the correlation coefficient between acrylamide level and TPCs $(r=-0.621)$ for oil treated with OTE at $400 \mathrm{mg}^{-1} \mathrm{~L} \mathrm{during}$ frying, and $(\mathrm{r}=$ 0.732) during heating model system.During the progressive frying of the potato chips, the sensory panel could distinguish a difference in flavor between the fried potato chips in sunflower oil with and without OTE or ORE. Panelists preferred the chips fried in oil treated with OTE or ORE.
\end{abstract}

Keywords: acrylamide, frying, heating rosemary, sensory evaluation, sunflower oil, thermal stability thyme.

*Corresponding author: El-Naggar E.A., 


\section{Introduction}

Deep fat frying can be defined as a process of control dehydration and browning with hot oils as the heat transfer medium (Che Man and Tan, 1999). During thermal treatments, the oil is exposed to elevated temperatures in the presence of air and moisture. A number of chemical reactions occur during this time, including oxidation and hydrolysis, as changes due to thermal decomposition (El-Naggar, 2007). These reactions generate several volatile and non-volatile decomposition products, which are responsible for deteriorating the quality of frying medium and are reported to pose health hazards (Singh and Tyagi, 2001). On the other hand, during deep fat frying, a rapid degradation of glyceridic fraction of oil is occurred and the acrylamide is a chemical compound that is formed. It is widely acknowledged that acrylamide, a potential carcinogen and neurotoxin which has raised an international health alarm since 2002, is generated from Millard reaction products (Esposito et al., 2017; Michalak et al., 2017; Zhang et al., 2008). In view of its recognized toxicity, several studies about metabolism, toxicokinetics and mutagenicity of acrylamide were carried out (Esposito et al., 2017). Extensive research has been carried out on the formation mechanism of this compound in foodstuff. Four main theories have been proposed to elucidate the formation mechanism: Theory 1: Direct formation from amino acids; Theory 2: Pathways based on acrolein intermediates, since acrolein has structural similarities to acrylamide. Acrolein can be formed by both of hydrolysis and oxidation of triacylglycerol (Nira et al., 2017). Theory 3: Pathways based on acrylic acid intermediate (Lindsay, 2002), and Theory
4: Pathways based on Millard browning precursors (Delgado et al., 2014; Mesias and Morales 2016; Michalak et al., 2017; Nira et al., 2017; Youssef et al., 2004). In this sense, the European Food Safety Agency (EFSA) has reconfirmed that acrylamide in food potentially increase the risk of developing certain types of cancer in all groups (EFSA, 2015).According to EFSA, the most important food groups contributing to acrylamide exposure are fried potato products (Mesias et al., 2016). The major reactants leading to the formation of acrylamide are sugars and asparagines at temperature above $120^{\circ} \mathrm{C}$ (Nira et al., 2017). The Millard reaction is the main responsible of the generation of flavor and color in thermally processed foods (Mesias et al., 2016). However, this reaction has been linked to the acrylamide formation, specifically with the presence of reducing sugar with groups capable of forming a Schiff base with the amino acid asparagine (Nira et $a l ., 2017)$. It has been generally known that in Streker degradation reaction, a Schiff base formation is the initial reaction step. (Jung et al., 2003). The detailed reaction mechanism for the formation of a Schiff base in the course of acrylamide formation is following: As shown in above reaction mechanism, Schiff base formation is an additionelimination reaction. (Gramza et al., 2006). However, the intake levels of acrylamide are likely to be higher. Thereafter, the consultation recognized that the issue of acrylamide in food is a major concern (FAO/WHO, 2002; United State and Drug Administration FDA, 2002). Ever since, it has been an urgent agenda to find out effective ways to limit the acrylamide formation during deep fat frying. The conversion of free non-protonated amine to protonated 
amine is easily obtained by lowering $\mathrm{pH}$ of the system (Jung et al., 2003), or by submerged for 30 or $60 \mathrm{~min}$. in one of the following solution: acetic acid 5\%; sodium bicarbonate 5\%; ascorbic acid $5 \%$; ethanol $70 \%$ or citric acid 5\% (ElBeltagy and Mubarak, 2005) or using $\mathrm{NaHCO} 3$ and $\mathrm{KHCO} 3$ (Nira et al., 2017), Wang et al. (2013) proved that $\mathrm{NaCl}$ could considerably inhibit the formation of acrylamide in mixtures of asparagine-glucose model system, or using antioxidant of bamboo leaves and extract of green tea on the formation and kinetics of acrylamide in an equimolar asparagine-glucose model system. Extract of bamboo leaves and green tea are demonstrated as a strong antioxidant applied in many food matrixed (Lee $e t$ al., 2002; Morales et al., 2014; Zhang et al., 2008), or using rosemary, sage and citric acid on the reduction of acrylamide formation (El-Naggar, 2010), or by treated of potato strips in one of the following ways prior to frying at different time and temperatures: soaking in distilled water and different solutions $\left(\mathrm{NaCl}, \mathrm{CaCl}_{2}\right.$ and citric acid); blanching in hot distilled water; blanching in hot distilled water, followed by soaking in different solutions $\left(\mathrm{NaCl}, \mathrm{CaCl}_{2}\right.$ and citric acid) and exposure to microwaves (El-Saied et al., 2008). Hence, addition of edible plant extracts in various products to exert their special effects is a novel technique for the reduction of acrylamide during thermal processing. Thus, the objective of this study was to investigate the possibility of the retarding the deterioration of sunflower oil during $24 \mathrm{~h}$ of intermittent deep fat frying or heating model systems and its relationship with the acrylamide formation level by the addition of BHA, oleoresin rosemary (ORE) and oleoresin thyme extracts (OTE), and sensory characteristics of the fried potato chips.

\section{Materials and methods}

\subsection{Materials}

Sunflower seed oil was obtained from Nile Oils and Detergents Company, Sohag, Egypt on May 2017. Potato tubers (Solanum tuberosum) were purchased from the local market of Assiut, Egypt on May 2017. They were cleaned, sorted, manually peeled using a sharp knife and then sliced with a mechanical slicer (about 2mm thickness). Oleoresin rosemary (ORE) (Rosmarinus officinalis) and oleoresin thyme extracts (OTE) (Thymus vulgaris) were obtained from the essential oils laboratory, National Research Center, Giza, Egypt (2017). The additional levels of both of ORE and OTE were dissolved in sunflower seed oil at $100,200,300,400,500$ and $600 \mathrm{mg} / \mathrm{kg}$. (Yanishlieva et al., 1997; Zhang et al., 2008). BHA was obtained from Sigma Chemical Co. (St Louis, Mo). HPLC Chemicals were obtained from Merch (Darmstadt, Germany). All other chemicals and solvents used were of analytical grade. Frying pans was stainless steel vessels (capacity $1500 \mathrm{~cm}^{3}$ ) with a $14 \mathrm{~cm}$ diameter and a $9.75 \mathrm{~cm}$ high used in frying process.

\subsection{Methods}

\subsubsection{Experimental design}

Fresh potatoes were peeled and sliced to a thickness of $2 \mathrm{~mm}$ using a mechanical slicer. They were kept submerged in 
distilled water at room temperature for one hour maximum before use (ElBeltagy and Mubarak, 2005).

\subsubsection{Frying experiments were carried out in various systems that contained}

Sunflower seed oil without antioxidants (control I); sunflower oil with $200 \mathrm{ppm}$ BHA (control II); sunflower oil with 100, 200, 300, 400, 500 and 600mg of ORE and/ or OTE per kilogram. Sunflower oil (one liter) was put into frying pan. The temperature was brought up to $60^{\circ} \mathrm{C}$, then the above concentration level of BHA, ORE and/ or OTE was added as above mentioned. The oil was stirred for $10 \mathrm{~min}$ to ensure dissolution of antioxidant. In the case of control I, the oil was held for 10 min at $60^{\circ} \mathrm{C}$, although no antioxidant was added. The temperature was then raised to $175^{\circ} \mathrm{C}$ during $20 \mathrm{~min}$. Frying started 20 min after the temperature had reached $175^{\circ} \mathrm{C}$. A batch of $100 \mathrm{gm}$ raw potato chips was fried for $8.5 \mathrm{~min}$ at $21.5 \mathrm{~min}$. Intervals for a period of $8 \mathrm{hrs}$ per day for three consecutive days. This is equivalent to 16 frying per day and 48 frying for three consecutive days. The fryer was left uncovered during the frying period. At the end of the per day of frying period, the fryer was switched off and the temperature was allowed to drop to $60^{\circ} \mathrm{C}$, about fifty milliliters of heated oil was withdrawn at the end every day and kept in brown bottles in freezer at $-10^{\circ} \mathrm{C}$ until used. After frying, the potato chips were removed from the fryer and toasted. The sixteen batches of potato chips each day was taken and labeled and packed in lowdensity polyethylene plastic bags for sensory evaluation. The evaluation was conducted on the same day that the frying was carried out.

\subsubsection{Chemical composition of wheat,} carob pods and wheat flour with different levels of carob pods powder used as a sugar or fat replacer

Chemical methods: The ORE and/or OTE were dissolved in sunflower oil at above different levels. A preliminary assessment of the antioxidant activity of ORE or OTE was made with the Rancimat method. The resistance to oxidation of absorbed oils has been measured using the Rancimat method and is expressed in units of time (=induction period). The difference between the induction period of oil and that of the same oil containing antioxidants is the basis for evaluation of the activity of these antioxidants. The effect of an antioxidant is termed the antioxidant index or protection factor (PF) and is expressed as the ratio of the induction periods for the stabilized and un-stabilized oil (Lalas and Dourtoglou, 2003). The temperature was set at $100^{\circ} \mathrm{C}$ $\pm 2^{\circ} \mathrm{C}$ and the airflow at $20 \mathrm{l} / \mathrm{hrs}$ (Abd-ElGhany, 2006). Total polar compounds (TPCs) were analyzed according to the method of (Xu, 2003). The content of the unchanged triglycerides, which determines the TPCs is a measure of the role of the ORE and/ or OTE for the retarding of thermal deterioration consequently, the acrylamide levels thiobarbituric acid (TBA) value was determined as malonaldehyde $/ \mathrm{kg}$ of oil using the method of AOAC, (2000). Acrylamide was determined using high performance liquid chromatography (HPLC) (Shimadzu HPLC, column C18 
ODS hypersil, $\operatorname{dim} 250 \times 4.6 \mathrm{~mm}$ ) as described by United State Food and Drug Administration, (2002) with a flow rate of $1 \mathrm{ml} / \mathrm{min}$ at $26^{\circ} \mathrm{C}$ and a wave length of $230 \mathrm{~mm}$ and amobile phase of 1 methanol: 1 acetic acid. The relative rate of change (RRC) was calculated by dividing the rate of change (RC) for the sunflower oil sample treated with ORE and/ or OTE by the rate of change (RC) for the control sample (Jaswir et al., 2000; Yanishlieva et al., 1997).

\subsubsection{Analysis and identification of oleoresin thyme and rosemary extracts}

Chemical compositions of oleoresin thyme and rosemary extracts were carried out by gas chromatography mass spectrum technique (GC/MS) according to the method described by Ozkan et al. (2010). Qualitative analysis was based on the comparison of retention times and the computer mass spectra libraries using Wiley GC/MS Library and Nist, Tutore Libraries. The percentage composition was computed from the GC peak areas.

\subsubsection{Sensory evaluation}

After the end of each day of frying, the potatoes chips were placed in plastic dishes for evaluation of their sensory quality. Ten panelists were selected from the food Science and Technology Department staff. Each sample was coded with a three-digit number. Panelists were required to evaluate the appearance, crispiness, flavor, greasiness and overall acceptability of each sample using a $10-$ point hedonic scale $(1=$ dislike extremely, $6=$ moderate, $10=$ like extremely) $($ Che
Man and Jaswir, 2000; Lalas and Dourtoglou, 2003). The procedure for the sensory evaluation was explained to the panelists before testing commenced.

\subsubsection{Statistical analysis}

Statistical analysis of effects of each antioxidant on induction period (IP), total polar compounds (TPCs), thiobarbituric acid (TBA) and acrylamide content (AA) were provided by statistical analyzed by one-way analysis of variance procedure using SAS (1985). The data obtained from sensory evaluation results were analyzed by ANOVA significant differences $(P<0.05)$ between treatment means (Ihekoronye and Ngoddy, 1985).

\section{Results and Discussion}

\subsection{Changes study of induction period,} total polar, malonaldehyde and acrylamide by addition of ORE/OTE during intermittent deep fat frying

To avoid or delay oil oxidation during thermal treatments, antioxidants are added to protect the oil from oxidation when exposed to high temperature. Thereupon, during the simulated thermal treatments of natural extracts may act as an antioxidant taking part in the chain radical oxidation, as well as simultaneously inhibiting the purely thermal processes occurring in the oil. A measure for the level of antioxidants and the participation of the extract in the oxidation as an antioxidant is the oxidation stability (induction period IP). 
The content of the changed in Table (1) showed that there were triacylglyceride, which determines the observed statistically significant total polar components (\% TPCs), which difference $(\mathrm{P} \leq 0.05)$ in induction period is a measure of the role of the additive (IP) for sunflower oil treated with a for retarding of thermal deterioration of oils. Beside TBA test, which is used as index for measuring oxidative rancidity (malonaldehyde formation), which take place in fried potatoes and a sensitive test for the decomposition products of highly unsaturated fatty acids. The obtained data different level of OTE and/or ORE compared with control samples There was a trend of decreased IP with increased frying period. In this concern, IP values were relatively increased by addition of OTE and/ or ORE up to 400 $\mathrm{mg} \mathrm{L}^{-1}$ in sunflower oil.

Table (1): Changes in induction period, total polar compounds, thiobarbituric acid and acrylamide content of sunflower oil treated with different levels of ORE and OTE during intermittent frying of potato chips for $24 \mathrm{hrs}$ at three consecutive days (8 hrs daily).

\begin{tabular}{|c|c|c|c|c|c|c|c|c|c|c|c|c|c|c|c|c|}
\hline \multirow{2}{*}{ Treatments } & \multirow{2}{*}{$\begin{array}{c}\text { Frying } \\
\text { time } \\
(\mathrm{hrs}) \\
\end{array}$} & \multirow[b]{2}{*}{ Control } & \multirow{2}{*}{$\begin{array}{c}\text { BHA } \\
200 \\
\mathrm{mg} / \mathrm{L}\end{array}$} & \multicolumn{6}{|c|}{ Concentration of oleoresin rosemary $(\mathrm{mg} / \mathrm{L})$} & \multicolumn{6}{|c|}{ Concentration of oleoresin thyme $(\mathrm{mg} / \mathrm{L})$} & \multirow{2}{*}{ जิ in } \\
\hline & & & & 100 & 200 & 300 & 400 & 500 & 600 & 100 & 200 & 300 & 400 & 500 & 600 & \\
\hline \multirow{4}{*}{$\begin{array}{l}\text { Induction period } \\
\text { (IP) (hrs.) }\end{array}$} & 0 & 30 & 40 & 45 & 50 & 55 & 60 & 53 & 52 & 51 & 56 & 60 & 65 & 62 & 59 & 3.06 \\
\hline & 8 & 29 & 38 & 40 & 44 & 54 & 59 & 56 & 50 & 45 & 51 & 57 & 64 & 58 & 55 & 4.06 \\
\hline & 16 & 27 & 35 & 36 & 40 & 47 & 58 & 51 & 49 & 40 & 46 & 52 & 62 & 53 & 50 & 4.61 \\
\hline & $\overline{24}$ & 21 & 30 & 33 & 37 & 44 & 56 & 49 & 47 & 37 & 42 & 50 & 60 & 50 & 48 & 4.06 \\
\hline L. S. D $5 \%$ & & 6.05 & 7.10 & 9.40 & 8.55 & 7.32 & 4.25 & 7.25 & 7.15 & 9.74 & 8.82 & 7.79 & 4.00 & 7.32 & 7.29 & \\
\hline PF & & --- & 1.42 & 1.57 & 1.76 & 2.09 & 2.66 & 2.33 & 2.23 & 1.76 & 2.0 & 2.38 & 2.85 & 2.38 & 2.28 & \\
\hline \multirow{4}{*}{$\begin{array}{l}\text { Total polar } \\
\text { compounds } \\
\text { (TPCs) \% }\end{array}$} & 0 & 6.5 & 6.15 & 5.80 & 5.0 & 5.0 & 4.9 & 4.95 & 5.55 & 5.25 & 5.0 & 4.5 & 4.2 & 4.4 & 4.5 & 1.06 \\
\hline & 8 & 10.40 & 8.50 & 8.00 & 7.69 & 7.45 & 6.7 & 7.15 & 7.8 & 6.86 & 6.65 & 6.44 & 6.3 & 6.4 & 6.76 & 2.35 \\
\hline & 16 & 17.30 & 14.45 & 13.84 & 11.49 & 9.97 & 7.5 & 8.75 & 9.5 & 12.11 & 10.76 & 9.41 & 7.1 & 7.5 & 7.85 & 3.06 \\
\hline & $\overline{24}$ & 22.25 & 19.30 & 18.46 & 17.10 & 14.5 & 10.4 & 10.68 & 11.45 & 16.68 & 14.01 & 12.4 & 8.8 & 9.30 & 9.95 & 4.3 \\
\hline L. S. D 5\% & & 4.83 & 4.85 & 4.23 & 4.04 & 3.00 & 2.55 & 3.05 & 2.38 & 3.98 & 4.06 & 3.39 & 3.06 & 2.23 & 2.35 & \\
\hline $\mathrm{RC}$ & & 242.30 & 213.82 & 218.3 & 216.6 & 190 & 112.24 & 115.75 & 106.3 & 217.7 & 180.2 & 175.5 & 109.5 & 111.3 & 121.11 & \\
\hline RRC & & --- & -13.25 & -17.03 & -23.14 & -34.8 & -53.25 & -52 & -48.5 & -25.03 & -37.03 & -44.26 & -60.44 & -56.2 & -55.3 & \\
\hline \multirow{4}{*}{$\begin{array}{l}\text { TBA } \\
\text { Malonaldehyde } \\
\mathrm{mg} / \mathrm{kg} \text { oil }\end{array}$} & 0 & 3.5 & 3.3 & 3.4 & 3.3 & 3.2 & 3.2 & 3.1 & 3.1 & 3.4 & 3.3 & 3.2 & 3.2 & 3.1 & 3.1 & 0.95 \\
\hline & 8 & 4.0 & 3.4 & 3.6 & 3.5 & 3.4 & 3.2 & 3.3 & 3.3 & 3.5 & 3.4 & 3.2 & 3.1 & 3.3 & 3.2 & 0.90 \\
\hline & 16 & 5.3 & 4.2 & 4.4 & 4.2 & 4.0 & 3.9 & 3.95 & 4.0 & 4.3 & 4.0 & 3.9 & 3.7 & 3.8 & 3.85 & 0.85 \\
\hline & 24 & 6.5 & 5.4 & 5.4 & 5.2 & 5.0 & 4.8 & 4.95 & 5.1 & 4.9 & 4.8 & 4.5 & 4.45 & 4.55 & 4.60 & 0.93 \\
\hline L. S. D 5\% & & 0.99 & 0.90 & 0.92 & 0.85 & 0.92 & 1.02 & 1.14 & 1.14 & 0.92 & 0.98 & 0.95 & 1.12 & 1.18 & 1.21 & --- \\
\hline $\mathrm{RC}$ & & 85.71 & 63.85 & 58.94 & 57.57 & 56.25 & 50 & 59.67 & 64.51 & 44.11 & 45 & 40.62 & 39.06 & 46.77 & 48.38 & \\
\hline RRC & & --- & -16.92 & -16.92 & -20 & -23.07 & -26.15 & -23.84 & -21.53 & -24.61 & -26.15 & -30.76 & -31.53 & -30 & -29.23 & \\
\hline \multirow{4}{*}{$\begin{array}{l}\text { Acrylamide (AC) } \\
\mu \mathrm{g} / \mathrm{kg} \text { oil }\end{array}$} & 0 & 1650 & 1656 & 1595 & 1580 & 1560 & 1550 & 1555 & 1565 & 1585 & 1560 & 1535 & 1530 & 1540 & 1545 & 32.14 \\
\hline & 8 & 1700 & 1411 & 1309 & 1258 & 1224 & 1190 & 1207 & 1275 & 1122 & 1088 & 1054 & 1020 & 1054 & 1150 & 25.90 \\
\hline & 16 & 1800 & 1530 & 1440 & 1404 & 1350 & 1332 & 1342 & 1386 & 1259 & 1224 & 1188 & 1116 & 1188 & 1224 & 28.32 \\
\hline & 24 & 1840 & 1600 & 1527 & 1490 & 1398 & 1370 & 1453 & 1490 & 1380 & 1324 & 1288 & 1196 & 1290 & 1343 & 31.06 \\
\hline L. S. D 5\% & & 143.3 & 171.0 & 310.7 & 315.2 & 321.3 & 347.5 & 325.7 & 265.5 & 316.17 & 319.6 & 326.5 & 353.7 & 331.2 & 269.9 & \\
\hline $\mathrm{RC}$ & & 11.51 & -3.38 & -4.26 & -5.69 & -10.38 & -11.61 & -6.55 & -4.79 & -12.93 & -15.12 & -16.09 & -21.8 & -16.33 & -13.07 & \\
\hline RRC & & --- & -13.04 & -17.01 & -19.02 & -24.02 & -25.54 & -21.03 & -19.02 & -25 & -28.04 & -30 & -35 & -29.8 & -27.01 & \\
\hline
\end{tabular}

Data in table were presented as mean of three replicates of one sample. $\mathrm{RC}=$ Rate of change, $\mathrm{RRC}=$ Relative rate of change, $\mathrm{PF}=$ Protection factor. The significant difference was evaluated by student's $\mathrm{T}$ test.

Thereupon, data illustrated that IP values of control samples ranged between 30 and 40hrs. at the beginning of the intermittent deep fat frying and ranged between 21 and 30hrs at the end of 24 hrs. of frying processes. It has long been recognized that the IP decreases with increasing frying time. This is consistent with the loss of antioxidants during frying periods. Moreover, the addition of 
$100 \mathrm{mg}$ and up to $600 \mathrm{mgL}^{-1}$ from OTE and/or ORE in oils slow down the decreasing of IP in comparison to the control samples. The $400 \mathrm{mgL}^{-1}$ of ORE addition treatment could be regarded as the critical effective concentration presenting maximum IP effect. There was a significant $(\mathrm{P} \leq 0.05)$ effect of the use of OTE and frying period on the IP. Similarly, the $400 \mathrm{mg} \mathrm{L}^{-1}$ of OTE addition level in the frying model technique could be considered as the best effective concentration. Hence, the IP values in the OTE-Technique system are obviously greater than the mitigation effect in the ORE-Technique system during intermittent deep fat frying. These differences might be attributed to the increasing of added portions of OTE and/ or ORE resulted in significant increasing of IP values, which may be attributed to the lower TPCs and TBA values, and also may be attributed to the chemical composition of them. The results are in agreement with those obtained by ElSaied et al. (2008), Zhang et al. (2008), Morales et al. (2014) and Delgado et al. (2014). There has been much scientific interest regarding the bioactive compounds which are protective constituents of plant products for their beneficial technique effects, in the prevention of unwanted constituents during deep fat fraying. Generally, results indicate that the samples of sunflower oil containing either OTE or ORE showed the least oxidation. Moreover, OTE seems to be a better antioxidant than ORE at the same level of addition. Also, its protective action is higher than that of BHA, which added to the sunflower oil at the maximum legally permitted level of addition, $200 \mathrm{mg} / \mathrm{L}$. This means that either OTE and/ or ORE additive acts as an inhibitor of the chain radical processes during intermittent deep fat frying. With respect to the content of total polar components (TPCs), which is used a measure of the role of the additive for the retarding of both oxidative and thermal changes. Several workers believed with a concentration of 25 $27 \%$ total polar component, frying oil is considered as deteriorated and should be discarded (Singh and Tyagi, 2001). The data in Table (1) indicated that TPCs was increased by increasing frying period. Moreover, the results demonstrate that the addition of the OTE or ORE to sunflower oil causes a slower increasing in TPCs content during intermittent deep fat frying in comparison to the increasing of TPCs in the control samples. The obtained data showed that there were observed significant difference $(\mathrm{P} \leq 0.05)$ in TPCs of sunflower oil treated either with OTE or ORE under different levels compared with control samples or frying periods. There was a trend of increased TPCs with increased frying period, the obtained data illustrated that TPCs content of control samples ranged between $6.15 \%$ and $6.5 \%$ at the beginning of the intermittent deep fat frying and ranged between $19.30 \%$ and $22.25 \%$ after the $24 \mathrm{hrs}$ of frying time. These results are in agreement with those obtained by Yanishlieva et al. (1997), El- 
Naggar (2010) and Zhang et al. (2012). As is evident from Table (1), the effect of OTE and/ or ORE on TPCs content is more pronounced at the $400 \mathrm{mg} 1-1$ concentration. It is worthy to mention that the TPCs content in the OTE technique system is obviously lesser than the mitigation effect in the ORE technique system during deep fat frying. Indeed, the $400 \mathrm{mg} \mathrm{l-1}$ of either OTE or ORE addition level in the frying model technique could be considered as the best effective concentration. Lalas and Dourtoglou (2003), Zyzak et al. (2003) and Zhang et al. (2012) have observed similar results in sunflower oil during intermittent deep fat frying of potato chips. Interestingly, the content of TPCs increased with the frying period due to accumulation of polar compounds in the oils as a result of degradation of hydro peroxides and/or dimerization or polymerization. This tendency was reported by Lee et al. (2002) and Zhang et al. (2012). Addition of natural antioxidants helped to reduce the accumulation of polar compounds in oil, especially in the early stage of frying, and it can act as a free radical scavenger to reduce lipid oxidation (Che Man and Jaswir, 2000; Jaswir et al., 2000; Singh and Tyagi, 2001; Zhang et al., 2012). Concerning thiobarbituric acid (TBA) test, which is used as an index for measuring oxidative rancidity, and a sensitive test for the decomposition products of highly unsaturated fatty acids. Same table clearly illustrated that the TBA values increases with increasing thermal treatment time. Findings showed that there were observed significant difference $(\mathrm{P} \leq 0.05)$ in TBA values of the oils treated either with OTE or ORE compared with control samples or frying periods. The oils treated with OTE was significantly $(P \leq 0.05)$ greater than that of the oil samples treated with ORE. The obtained data declared that TBA values of control samples ranged between 3.3 and $3.5 \mathrm{mg}$ malonaldehyde $/ \mathrm{kg}$ oil at the beginning of the thermal treatments and ranged between 5.45 and $6.5 \mathrm{mg}$ malonaldehyde $/ \mathrm{kg}$ oil at the end of frying periods. These results are in agreement with those obtained by Lalas and Dourtoglou (2003). Moreover, it is interested to indicate that addition of OTE and/ or ORE to sunflower oil at different levels during intermittent deep fat frying minimized the observed increase in TBA values of $400 \mathrm{mgL}^{-1}$. It is worth mentioning that the TBA values in the OTE - technique system is obviously lower than the mitigation effect in the ORE - technique system during intermittent deep fat frying. Che Man and Jaswir (2000), Bandonieme et al. (2002) and Zhang et al. (2008) have found similar results in sunflower oil during intermittent deep fat frying of potatoes chips. Interestingly, I wanted to explore the impact of acrylamide formation. Acrylamide is produced naturally in foods with a high carbohydrate content and a low protein composition that when subjected to deep fat frying, generate this toxin mainly through Millard reaction (Gertz and 
Klostermann, 2002; Morales et al., 2014). Acrylamide content was determined in sunflower oil treated with $100,200,300,400,500$ and $600 \mathrm{mgL}^{-1}$ of OTE or ORE by HPLC analytical method. It was amazing to find a dramatic reduction of acrylamide by addition of such a small quantity of OTE and/or ORE before thermal treatment. The result in Table (1) showed that the acrylamide level of sunflower oil increased progressively with the frying time. This is consistent with the loss of antioxidants during thermal periods. Moreover, the addition of OTE or ORE slows down the increasing of acrylamide level. The obtained data declared that there were noticed statistically significant difference $(\mathrm{P} \leq 0.05)$ in acrylamide level of sunflower oil treated with a different concentration of OTE and/or ORE compared with control samples and frying periods. Findings illustrated that acrylamide level of control samples ranged between 1650 and $1656 \mu \mathrm{g} / \mathrm{kg}$ oil at the beginning of the thermal treatment and ranged between 1600 and $1840 \mu \mathrm{g} / \mathrm{kg}$ oil after the $24 \mathrm{hrs}$. of intermittent deep fat frying. The results obtained in this part of the study are similar to those reported by El-Naggar (2010) and Morales et al. (2014). As regarding acrylamide reduction, the OTE technique system $400 \mathrm{mgL}^{-1}$ exhibited a higher percentage $(35 \%)$ than obtained with ORE - technique system $400 \mathrm{mg} \mathrm{L}^{-1}$ $(25.54 \%)$, and with BHA (13.04\%), which was used as control. However, it should be observed that BHA was used as a pure substance, whereas the antioxidant extracts (ORE or OTE) were composed of complex mixtures of compounds. This observation suggests that the antioxidant protection can vary according to different compounds and the synergistic effects betweenthem (Jung et al., 2003). Morales et al. (2014) reported that the thyme plant species has high antioxidant activity. In these plants, compounds such as ocimene, camphene, terpinene 4 - acetate and $\gamma$ terpinene have been identified, which can stabilize free radicals the reduction rates of acrylamide in the OTE - technique system are obviously greater than the mitigation effect in the ORE - technique during intermittent deep fat frying. Moreover, it is interested to indicate that addition of OTE or ORE to sunflower oil during deep fat frying minimized the observed increase in acrylamide level of $400 \mathrm{mg} / \mathrm{L}$. Generally, acrylamide formation levels are accompanied by increased both of TPCs and TBA. In this study, both of OTE or ORE - technique systems showed significantly $(\mathrm{P} \leq 0.05)$ less formation of acrylamide compared to the BHA - technique system and the oil sample without antioxidants (control). These results indicate that the stabilizing and acrylamide formation reduction of antioxidants on sunflower oil were in the order: OTE > ORE > BHA. The results in Table (1) enabled us to determine the relative effects (in comparison to the control samples) of the additive on the rate of change of $\left(R_{R C} C_{\mathrm{TPC}}, \mathrm{RRC}_{\mathrm{TBA}}\right.$ and $\mathrm{RRC}_{\mathrm{AC}}$ ), and rates of change of the 
$\mathrm{RC}_{\mathrm{TPC}} \%, \mathrm{RC}_{\mathrm{TBA}} \mathrm{mg} \mathrm{L}^{-1}$ and $\mathrm{RC}_{\mathrm{AC}}$. The values for $\mathrm{RC}$ and $\mathrm{RRC}$ obtained are presented in Table (1). The comparison of the data for $\mathrm{RRC}_{\mathrm{TPCs}}$ with those for both of $\mathrm{RRC}_{\mathrm{TBA}}$ and $\mathrm{RRC}_{\mathrm{AC}}$ shows that the OTE or ORE causes a stronger inhibiting action on the oxidative processes than on the changes of the TBA or AC. Findings indicated that using OTE causes a stronger inhibiting action on the oxidative processes than ORE, consequently, causes a reduction on $\mathrm{TPC}_{\mathrm{s}}, \mathrm{TBA}$ and $\mathrm{AC}_{\mathrm{s}}$ values. On the other hand, the comparison of the results for relative rate of change $\mathrm{R} \mathrm{RC}_{\mathrm{TPC}}$ with those for $\mathrm{RRC}_{\mathrm{TBA}}$ and $\mathrm{RRC}_{\mathrm{AC}}$ illustrates that the OTE and/ or ORE causes a higher change than on the changes of the acrylamide level then TBA value. The values for sunflower oil samples treated with ORE show a linear correlation between the $\mathrm{PF}$ and the relative rates of change for TPCs $(r=-0.968)$, TBA $(r=-$ $0.966)$ and $\mathrm{AC}_{\mathrm{s}}(\mathrm{r}=-0.862)$.

Table (1): Changes in induction period, total polar compounds and acrylamide contents of sunflower oil treated with different levels of ORE and OTE during intermittent heating for $24 \mathrm{hrs}$ at three consecutive days (8 hrs daily).

\begin{tabular}{|c|c|c|c|c|c|c|c|c|c|c|c|c|c|c|c|c|}
\hline \multirow{2}{*}{ Treatments } & \multirow{2}{*}{$\begin{array}{l}\text { Heating } \\
\text { time } \\
(\mathrm{hrs}) \\
\end{array}$} & \multirow[b]{2}{*}{ Control } & \multirow{2}{*}{$\begin{array}{c}\mathrm{BHA} \\
200 \\
\mathrm{mg} / \mathrm{L} \\
\end{array}$} & \multicolumn{6}{|c|}{ Concentration of oleoresin rosemary $(\mathrm{mg} / \mathrm{L})$} & \multicolumn{6}{|c|}{ Concentration of oleoresin thyme $(\mathrm{mg} / \mathrm{L})$} & \multirow[b]{2}{*}{ जิ in } \\
\hline & & & & 100 & 200 & 300 & 400 & 500 & 600 & 100 & 200 & 300 & 400 & 500 & 600 & \\
\hline \multirow{4}{*}{$\begin{array}{l}\text { Induction period } \\
\text { (IP) (hrs.) }\end{array}$} & 0 & 30 & 40 & 45 & 50 & 55 & 60 & 53 & 52 & 51 & 56 & 60 & 65 & 62 & 59 & 3.39 \\
\hline & 8 & 26 & 37 & 39 & 42 & 51 & 55 & 52 & 50 & 40 & 44 & 55 & 58 & 56 & 55 & 3.98 \\
\hline & 16 & 23 & 33 & 34 & 38 & 45 & 53 & 51 & 49 & 38 & 40 & 47 & 55 & 54 & 53 & 4.61 \\
\hline & 24 & 20 & 27 & 30 & 35 & 40 & 48 & 47 & 46 & 33 & 37 & 44 & 51 & 50 & 49 & 4.83 \\
\hline L.S. D $5 \%$ & & 6.05 & 7.74 & 9.74 & 9.89 & 9.53 & 3.83 & 8.59 & 7.64 & 10.14 & 10.53 & 7.70 & 3.79 & 9.78 & 7.79 & \\
\hline$\overline{\mathrm{PF}}$ & & --- & 1.35 & 1.50 & 1.75 & 2.0 & 2.4 & 2.35 & 2.30 & 1.65 & 1.85 & 2.2 & 2.55 & 2.50 & 2.45 & \\
\hline \multirow{4}{*}{$\begin{array}{l}\text { Total polar } \\
\text { compounds } \\
\text { (TPCs) } \%\end{array}$} & 0 & 6.5 & 6.15 & 5.80 & 5.0 & 5.0 & 4.9 & 4.95 & 5.55 & 5.25 & 5.0 & 4.5 & 4.2 & 4.4 & 4.5 & 1.03 \\
\hline & 8 & 12.8 & 10.30 & 8.5 & 8.00 & 7.75 & 7.15 & 7.85 & 8.10 & 8.10 & 7.80 & 7.65 & 7.5 & 7.9 & 7.95 & 2.41 \\
\hline & 16 & 20.25 & 15.5 & 14.5 & 12.40 & 10.65 & 7.80 & 8.30 & 9.20 & 13.4 & 12.44 & 12.3 & 11.30 & 13.15 & 13.3 & 3.15 \\
\hline & 24 & 23.5 & 20.4 & 20.85 & 18.34 & 15.70 & 10.25 & 12.55 & 14.35 & 17.5 & 15.60 & 14.2 & 13.4 & 15.4 & 15.5 & 4.54 \\
\hline L. S. D 5\% & & 4.87 & 4.82 & 5.33 & 5.17 & 4.63 & 2.91 & 3.84 & 4.73 & 5.07 & 4.80 & 4.10 & 4.06 & 4.22 & 308 & \\
\hline & & 261.53 & 231.7 & 259.5 & 233.45 & 214 & 109.18 & 153.53 & 158.55 & 233.33 & 218.36 & 215.55 & 204.5 & 250 & 244.4 & \\
\hline RRC & & --- & -13.19 & -11.27 & -21.95 & -33.19 & -35.10 & -46.59 & -38.9 & -25.53 & -33.61 & -39.57 & -42.57 & -34.46 & -34.04 & \\
\hline \multirow{4}{*}{$\begin{array}{l}\text { TBA } \\
\text { Malonaldehyde } \\
\mathrm{mg} / \mathrm{kg} \text { oil }\end{array}$} & 0 & 3.6 & 3.4 & 3.5 & 3.45 & 3.4 & 3.3 & 3.35 & 3.4 & 3.3 & 3.3 & 3.25 & 3.30 & 3.3 & 3.33 & 0.99 \\
\hline & 8 & 5 & 4.5 & 4.8 & 4.75 & 4.7 & 4.5 & 4.7 & 4.75 & 4.6 & 4.5 & 4.45 & 4.4 & 4.5 & 4.55 & 0.92 \\
\hline & 16 & 6.2 & 5.8 & 5.9 & 5.8 & 5.7 & 5.4 & 5.5 & 5.55 & 5.7 & 5.6 & 5.4 & 5.2 & 5.3 & 5.4 & 0.90 \\
\hline & 24 & 7.3 & 6.9 & 7.0 & 6.85 & 6.75 & 6.5 & 6.6 & 6.65 & 6.8 & 6.7 & 6.5 & 6.4 & 6.5 & 6.55 & 0.94 \\
\hline L. S. D 5\% & & 0.81 & 0.86 & 1.09 & 0.92 & 0.96 & 1.06 & 1.03 & 1.10 & 0.97 & 0.84 & 1.05 & 0.95 & 1.04 & 1.07 & \\
\hline $\mathrm{RC}$ & & 102.7 & 102.94 & 100 & 98.55 & 98.5 & 96.96 & 97.01 & 95.58 & 106.06 & 100.03 & 100 & 93.93 & 96.96 & 96.69 & \\
\hline RRC & & --- & -5.47 & -4.10 & -6.16 & -7.53 & -10.95 & -9.58 & -8.90 & -6.84 & -8.21 & -10.95 & -12.32 & 10.95 & 10.27 & \\
\hline \multirow{4}{*}{$\begin{array}{l}\text { Acrylamide (AC) } \\
\mu \mathrm{g} / \mathrm{kg} \text { oil }\end{array}$} & 0 & 1650 & 1656 & 1595 & 1580 & 1560 & 1550 & 1555 & 1565 & 1585 & 1560 & 1535 & 1530 & 1540 & 1545 & 27.71 \\
\hline & 8 & 1665 & 1350 & 1285 & 1238 & 1175 & 1150 & 1270 & 1300 & 1110 & 1065 & 1045 & 980 & 1060 & 1160 & 26.90 \\
\hline & 16 & 1965 & 1400 & 1340 & 1290 & 1230 & 1200 & 1330 & 1345 & 1150 & 1110 & 1080 & 1010 & 1095 & 1185 & 32.14 \\
\hline & 24 & 1710 & 1450 & 1395 & 1350 & 1290 & 1240 & 1370 & 1380 & 1190 & 1135 & 1125 & 1040 & 1125 & 1220 & 33.03 \\
\hline L. S. D 5\% & & 134.8 & 168.4 & 310.7 & 320.73 & 328.08 & 350.42 & 330.9 & 375.23 & 314.17 & 319.57 & 327.2 & 353.34 & 330.9 & 272.6 & \\
\hline $\mathrm{RC}$ & & 3.63 & -9.37 & -12.53 & -14.55 & -17.39 & -20 & -11.89 & -11.82 & -24.9 & -27.24 & -26.71 & -32.02 & -26.94 & -21.03 & \\
\hline RRC & & --- & -15.20 & -18.42 & -21.05 & -24.56 & -27.48 & -19.88 & -19.29 & -30.40 & -33.62 & -34.20 & -39.18 & -34.21 & -28.65 & \\
\hline
\end{tabular}

Data in table were presented as mean of three replicates of one sample. $\mathrm{RC}=$ Rate of change, $\mathrm{RRC}=$ Relative rate of change, $\mathrm{PF}=$ Protection factor. The significant difference was evaluated by student's Ttest.

Meanwhile, values for sunflower oil treated with OTE show a linear correlation between the $\mathrm{PF}$ and the relative rates of changes of $\mathrm{TPC}_{\mathrm{s}}(\mathrm{r}=$ -
0.890), TBA $(\mathrm{r}=-0.943)$ and $\mathrm{AC}_{\mathrm{s}}(\mathrm{r}=$ 0.935) (table 2). It is interesting to discuss the data in Table (1), to check that the effective of OTE and/or ORE for 
the reduction of the oxidative processes and acrylamide level in real food system was simply due to its antioxidants property, another experiment was carried out for studding the oxidative processes and acrylamide formation level during heating model system (similar to that of the frying model system except that, no addition of potato chips), of 100, 200, $300,400,500$ and $600 \mathrm{mgL}^{-1}$ of OTE and/or ORE. Similar to intermittent deep fat frying, the intermittent heating model .In general, results obtained in this study were closely related to the intermittent deep fat frying as described above.

3.2 Changes study of induction period, total polar, malonaldehyde and acrylamide by addition of ORE/OTE during intermittent deep fat heating

Heating model technique was carried out to maintain the relationship between thermal deterioration of sunflower oil treated with different levels of OTE and/or ORE and acrylamide level. Results of IP values determine of oil during intermittent heating model system revealed that heating period, use of BHA and natural antioxidants in this study has a significantly $(\mathrm{P} \leq 0.05)$ effect on the all values. There was a trend of decreased IP with increased heating period. IP values was decreased from $30 \mathrm{hrs}$ to 20 hrs, for first control and from 40 to 27 hrs for second control, while for OTE and/or ORE treatments at $400 \mathrm{mg} \mathrm{L}^{-}$ ${ }^{1}$ were decreased from 65 to $51 \mathrm{hrs}$ and from 60 to $48 \mathrm{hrs}$, respectively. Hence, results show that OTE or ORE could significantly $(\mathrm{P} \leq 0.05)$ reduce the oil oxidation processes during heating model system. The relatively higher IP values shown by the samples using the two antioxidants compared to the value of first control sample could be caused by the ability of the antioxidant to retard the deterioration of the oil during heating. It is worth mentioning that, results of TPCs, TBA and ACs analysis of oils during intermittent heating model system revealed that heating period and use of BHA or natural antioxidants in this study have a significant $(\mathrm{P} \leq 0.05)$ effect on the content. Hence, results show that OTE or ORE could significantly $(\mathrm{P} \leq 0.05)$ reduce the oil deterioration during intermittent heating. The PF of heating model system oil samples treated with antioxidants were significantly more decreased than of the frying oil samples under the same condition. Thereupon, TPCs, TBA and ACs were a marked decreased. The lower TPCs, TBA and ACs values of oil samples treated either with thyme or rosemary was due to the antioxidant activity of both materials. The values for $\mathrm{RC}$ and RRC obtained are presented in Tables $(1,2)$. The rate of change values during heating model system show that the OTE or ORE causes a higher change than rate of change values during frying model system. Also, relative rate of change values during heating model system illustrates that the OTE or ORE causes a higher relatively rate of changes than frying model technique. During heating model technique, the all values of 
oil sample treated with ORE shows a linear correlation between the $\mathrm{PF}$ and the relative rate of change for TPCs $(r=-$ $0.944)$, TBA $(r=-0.945)$ and ACs $(r=-$ 0.520 ). Meanwhile, all values of oil samples treated with OTE shows also a liner correlation between $\mathrm{PF}$ and relative rate of change of TPCs $(r=-0.725)<$ TBA ( $r=-0.933)$ and ACs ( $r=0.389)$. However, a positive proportional relationship was found between the TPCs and ACs where $r=0.218$ for oil treated with ORE and $\mathrm{r}=0.916$ for oil treated with OTE during frying model system. While, $r=0.473$ for oil treated with ORE and $r=0.643$ for oil treated with OTE during heating model system. The slope of this correlation depends on the type and additive substance level. The comparison of the data for PF with those for relative rates of change for TPCs, TBA and ACs show that the OTE causes a stronger inhibiting action on the deterioration processes of oil than ORE. The rate of changes of TPC, TBA and $\mathrm{AC}$ content in the heating model system treated with antioxidants were significantly greater than that of the frying model system under the same conditions. Thus, consequently the relative rates of change for acrylamide decreases with increasing the levels of OTE and/or ORE up to $400 \mathrm{mgL}^{-1}$ of sunflower oil.

Table (3): Relationship between acrylamide level and frying time, IP, TPCs and TBA with the best mathematical model of acrylamide level of sunflower oil treated with different level of ORE or OTE during intermittent frying of potato chips for $24 \mathrm{hrs}$ at three consecutive days ( $8 \mathrm{hrs}$ daily).

\begin{tabular}{|c|c|c|c|c|}
\hline Trial & Frying time & IP & TPCs & TBA \\
\hline \multirow{2}{*}{ Control } & $\gamma=-190.9+0.116 X$ & $\gamma=98.13-0.041 \mathrm{X}$ & $\gamma=1572.3+12.5 X$ & $\gamma=1440+63.7 X$ \\
\hline & $\mathrm{r}=0.986$ & $\mathrm{r}=-0.888$ & $r=0.994$ & $r=0.980$ \\
\hline \multirow{2}{*}{ BHA } & $\gamma=21.1-5.86 X$ & $\gamma=42-4.028 X$ & $\gamma=1528.3+1.73 X$ & $\gamma=1440.5+26 X$ \\
\hline & $\mathrm{r}=0.059$ & $\mathrm{r}=0.098$ & $r=0.097$ & $r=0.245$ \\
\hline \multicolumn{5}{|l|}{$\overline{\text { ORE }}$} \\
\hline $100 \mathrm{mg} / \mathrm{L}$ oil & $r=-0.076$ & $\mathrm{r}=0.173$ & $\mathrm{r}=0.083$ & $r=0.175$ \\
\hline $200 \mathrm{mg} / \mathrm{L}$ oil & $\mathrm{r}=-0.117$ & $\mathrm{r}=0.259$ & $\mathrm{r}=0.014$ & $r=0.134$ \\
\hline $300 \mathrm{mg} / \mathrm{L}$ oil & $\mathrm{r}=-0.334$ & $\mathrm{r}=0.115$ & $r=-0.243$ & $\mathrm{r}=-0.093$ \\
\hline \multirow[t]{2}{*}{$400 \mathrm{mg} / \mathrm{L}$ oil } & $\gamma=1420.2-5 X$ & ----- & $\gamma=1514.5-20.9 X$ & ----- \\
\hline & $\mathrm{r}=-0.346$ & $\mathrm{r}=0.249$ & $r=-0.323$ & $r=-0.014$ \\
\hline \multirow[t]{2}{*}{$500 \mathrm{mg} / \mathrm{L}$ oil } & & $\gamma=2771-26.5 X$ & & \\
\hline & $\mathrm{r}=-0.147$ & $r=-0.528$ & $r=-0.197$ & $\mathrm{r}=0.110$ \\
\hline \multirow[t]{2}{*}{$600 \mathrm{mg} / \mathrm{L}$ oil } & & & & $\gamma=1345+21.5 X$ \\
\hline & $\mathrm{r}=-0.116$ & $\mathrm{r}=0.167$ & $r=-0.164$ & $r=0.153$ \\
\hline \multicolumn{5}{|l|}{$\overline{\mathrm{OTE}}$} \\
\hline $100 \mathrm{mg} / \mathrm{L}$ oil & $r=-0.314$ & $\mathrm{r}=0.423$ & $r=-0.124$ & $r=-0.062$ \\
\hline $200 \mathrm{mg} / \mathrm{L}$ oil & $\mathrm{r}=-0.370$ & $\mathrm{r}=0.400$ & $r=-0.228$ & $r=-0.087$ \\
\hline $300 \mathrm{mg} / \mathrm{L}$ oil & $r=-0.385$ & $r=0.374$ & $r=-0.296$ & $r=-0.069$ \\
\hline \multirow[t]{2}{*}{$400 \mathrm{mg} / \mathrm{L}$ oil } & $\gamma=41.9-0.025 X$ & $\gamma=-15592+363 X$ & $\gamma=1691.4-72.11 \mathrm{X}$ & --- \\
\hline & $\mathrm{r}=-0.527$ & $\mathrm{r}=0.897$ & $r=-0.621$ & $r=-0.133$ \\
\hline \multirow[t]{2}{*}{$\overline{500 \mathrm{mg} / \mathrm{L} \text { oil }}$} & & & & $\gamma=1465-53.5 X$ \\
\hline & $\mathrm{r}=-0.387$ & $\mathrm{r}=0.400$ & $r=-0.449$ & $r=-0.168$ \\
\hline $600 \mathrm{mg} / \mathrm{L}$ oil & $r=-0.398$ & $\mathrm{r}=0.460$ & $r=-0.452$ & $r=-0.122$ \\
\hline
\end{tabular}

TPCS=Total Polar compounds. ORE $=$ Oleoresin rosemary extract. OTE $=$ Oleoresin thyme extract. TBA= Thiobarbituric acid. 
Table (4): Relationship between acrylamide level and heating time, IP, TPCs and TBA with the best mathematical models of acrylamide level of sunflower oil treatment with different levels of ORE or OTE during intermittent heating for $24 \mathrm{hrs}$ at three consecutive days ( $8 \mathrm{hrs}$ daily).

\begin{tabular}{|c|c|c|c|c|}
\hline Trial & Heating time & IP & TPCs & TBA \\
\hline \multirow[t]{2}{*}{ Control } & $\gamma=1648.5+2.63 X$ & $\gamma=1836-6.3 \mathrm{X}$ & $\gamma=1624+3.5 X$ & $\gamma=1586+17 X$ \\
\hline & $\mathrm{r}=0.989$ & $\mathrm{r}=-0.982$ & $\mathrm{r}=0.992$ & $r=0.987$ \\
\hline \multirow[t]{2}{*}{$\overline{\mathrm{BHA}}$} & $\gamma=1510-5 X$ & $\gamma=1215+6.9 X$ & $\gamma=1550.3-7.66 \mathrm{X}$ & $\gamma=11992+3244 X$ \\
\hline & $r=-0.478$ & $\mathrm{r}=0.356$ & $r=-0.439$ & $\mathrm{r}=0.757$ \\
\hline \multicolumn{5}{|l|}{$\overline{\text { ORE }}$} \\
\hline $100 \mathrm{mg} / \mathrm{L}$ oil & $\mathrm{r}=-0.520$ & $\mathrm{r}=0.587$ & $\mathrm{r}=-0.370$ & $r=-0.556$ \\
\hline \multirow[t]{2}{*}{$200 \mathrm{mg} / \mathrm{L}$ oil } & & $\gamma=673+17 X$ & $\gamma=2288-114.2 X$ & \\
\hline & $r=-0.546$ & $r=0.722$ & $r=-0.916$ & $r=0.590$ \\
\hline $300 \mathrm{mg} / \mathrm{L}$ oil & $r=-0.570$ & $r=0.517$ & $r=-0.473$ & $r=-0.618$ \\
\hline \multirow[t]{2}{*}{$400 \mathrm{mg} / \mathrm{L}$ oil } & $\gamma=1417-11 X$ & $\gamma=35.8+24.5 X$ & $\begin{array}{ll}---- \\
\end{array}$ & \\
\hline & $\mathrm{r}=-0.629$ & $r=0.673$ & $r=-0.642$ & $r=-0.659$ \\
\hline $500 \mathrm{mg} / \mathrm{L}$ oil & $r=-0.519$ & $r=0.600$ & $r=-0.502$ & $r=-0.588$ \\
\hline $600 \mathrm{mg} / \mathrm{L}$ oil & $r=-0.565$ & $r=0.524$ & $\mathrm{r}=-0.460$ & $r=-0.630$ \\
\hline \multicolumn{5}{|l|}{ OTE } \\
\hline $100 \mathrm{mg} / \mathrm{L}$ oil & $r=-0.672$ & $r=0.855$ & $\mathrm{r}=-0.597$ & $r=-0.702$ \\
\hline \multirow[t]{2}{*}{$200 \mathrm{mg} / \mathrm{L}$ oil } & & $\gamma=133+24.5 X$ & & \\
\hline & $r=-0.689$ & $\mathrm{r}=0.888$ & $r=-0.649$ & $r=-0.705$ \\
\hline $300 \mathrm{mg} / \mathrm{L}$ oil & $r=-0.676$ & $r=0.679$ & $r=-0.687$ & $r=-0.705$ \\
\hline \multirow[t]{2}{*}{$400 \mathrm{mg} / \mathrm{L}$ oil } & $\gamma=1356-18 X$ & ---- & $\gamma=1577.4-47.8 X$ & $\gamma=1830-143 X$ \\
\hline & $\mathrm{r}=-0.711$ & $r=0.825$ & $\mathrm{r}=-0.732$ & $\mathrm{r}=-0.715$ \\
\hline $500 \mathrm{mg} / \mathrm{L}$ oil & $r=-0.694$ & $r=0.808$ & $r=-0.698$ & $r=-0.715$ \\
\hline $600 \mathrm{mg} / \mathrm{L}$ oil & $r=-0.681$ & $\mathrm{r}=0.711$ & $r=-0.660$ & $r=-0.708$ \\
\hline
\end{tabular}

$\mathrm{I} p=$ Induction period. TPCS=Total Polar compounds. ORE $=$ Oleoresin rosemary extract. OTE $=$ Oleoresin thyme extract. TBA= Thiobarbituric acid.

\subsection{Relationship between acrylamide} level and thermal treatment time, IP, TPCs and TBA with the best mathematical models of acrylamide level

It is interesting to discuss the results in Tables $(3,4)$. The correlation between acrylamide level and both of frying time, IP, $\mathrm{TPC}_{\mathrm{s}}$ and TBA are discussed. Acrylamide formation level in frying model system using oil samples treated with OTE was higher correlated for frying time $(r=-0.527)$, IP $(r=-897)$, TPCs $(r=-621)$ and TBA $(r=-0.168)$ than oil samples treated with ORE which was correlated for frying time $(r=-0.346)$, IP $(r=-0.528)$, TPCs $(r=-0.323)$ and TBA $(\mathrm{r}=-0.153)$. Besides, results in same Tables clearly showed the best mathematical models of acrylamide level of sunflower oil traded with OTE and/ or ORE during intermittent thermal treatments for $24 \mathrm{hrs}$ at three consecutive days ( 8 hrs daily) could be predicted from the simple regression equation (Table 3 ). On the other hand, acrylamide level in heating model system using oils treated with OTE was higher correlated with heating time $(r=-0.711)$, IP $(r=0.888)$, TPCs $(r=-0.732)$ and TBA $(r=-0.715)$ than oil samples treated with ORE which was correlated for heating time ( $\mathrm{r}=$ 0.629), IP $(r=0.673)$, TPCs $(r=-0.916)$ and TBA $(r=0.673)$, TPCs $(r=-0.916)$ and TBA $(r=0.757)$. Results obtained showed the best mathematical models of acrylamide level of the oils treated with ORE or OTE during heating model 
system for $24 \mathrm{hrs}$ at three consecutive days ( 8 hrs daily) could be predicted from the simple regression (Table 4). From the above data, it could be observed that using OTE or ORE up to $400 \mathrm{mg} \mathrm{L}^{-1}$ of sunflower oil had the highest inhibitory effect on the thermal deterioration of oil, consequently acrylamide formation level in potato chips. Whereas, the acrylamide level in potato chips samples treated with OTE and/ or ORE was within the permissible level, while the control potato chips contained a higher content of acrylamide than the permissible level, as reported by WHO (2005) and Meghavanam and Janakiraman (2017).

Table (5): Chemical analysis and identification of OTE and ORE.

\begin{tabular}{|c|c|c|c|c|c|c|}
\hline Peak No. & $\begin{array}{l}\text { Retention time } \\
\text { (min.) }\end{array}$ & Components of OTE & $\%$ & $\begin{array}{l}\text { Retention time } \\
\text { (min.) }\end{array}$ & Components of ORE & $\%$ \\
\hline 1 & 5.63 & $\gamma-$ Terpinen & 2.85 & 5.63 & $\gamma-$ Terpinene & 10.20 \\
\hline 2 & 5.74 & Ocimene & 3,50 & 5.74 & Ocimene & 1.30 \\
\hline 3 & 5.98 & Isolimonene & 2.50 & 5.97 & Camphene & 4.95 \\
\hline 4 & 6.37 & $(+)$-Camphene & 0.95 & 6.37 & $\alpha$-Pinene & 4.30 \\
\hline 5 & 6.53 & $\beta$-Pinene & 3.00 & 6.96 & Terpinen 4 - acetate & 4.25 \\
\hline 6 & 6.94 & Terpinene 4 - acetate & 5.50 & 7.13 & D - Limonene & 11.50 \\
\hline 7 & 7.13 & Cinnamyl alcohol & 17.10 & 7.17 & 1, 8 -Cineole & 3.50 \\
\hline 8 & 7.21 & Cineole & 1.20 & 7.69 & Cis - Piperitol & 4.51 \\
\hline 9 & 7.55 & Artemesia triene & 10.5 & 8.16 & Dihydrocarveol & 4.20 \\
\hline 10 & 7.67 & 1 - Terpinenol & 1.55 & 8.42 & $\beta-$ Terpinol & 1.55 \\
\hline 11 & 8.07 & Linalool & 5.85 & 9.22 & Isogeraniol & 9.20 \\
\hline 12 & 8.73 & Camphor & 1.30 & 9.35 & $\alpha-$ Terpineol & 12.5 \\
\hline 13 & 8.90 & Borneol & 3.10 & 9.38 & Anethole & 0.70 \\
\hline 14 & 9.10 & 4 - Terpineol & 3.20 & 9.95 & Linalyl acetate & 3.50 \\
\hline 15 & 9.71 & Thymol methyl ether & 2.50 & 10.51 & $\alpha-$ Ionone & 1.44 \\
\hline 16 & 10.36 & Thymol & 5.50 & 10.93 & Linalool & 6.50 \\
\hline 17 & 10.53 & Carvacrol & 15.5 & 11.92 & Caryophyllene & 4.49 \\
\hline 18 & 10.61 & Anisole, 2, 3, 6 trimethyl & 2.60 & 12.83 & $\beta$ - Gurjunene & 0.90 \\
\hline 19 & 11.92 & Caryophyllene & 9.40 & 13.11 & Camphor & 8.95 \\
\hline 20 & 12.43 & $\gamma$ - Muurolene & 0.90 & 13.52 & Spathulenol & 0.91 \\
\hline 21 & 12.90 & $\delta$ - Cadinene & 1.35 & 13.68 & Guaiol & 0.65 \\
\hline 22 & 13.96 & $\gamma$ - Eduesmol & 0.10 & --- & & --- \\
\hline
\end{tabular}

$\mathrm{OTE}=$ Oleoresin thyme extract. $\mathrm{ORE}=$ Oleoresin rosemary extract.

\subsection{Chemical analysis and identification of OTE and ORE}

In an attempt to define the identify and roles played by chemical composition of (OTE) and (ORE) as antioxidants gas chromatography mass spectrum technique (GC/MD) as declared by preliminary determinations was used to fractionate and identify these compounds. From the data tabulated on Table (5), it could be noticed that there were 21 components defined in ORE and 22 components for OTE. The major components for ORE were $\alpha$ - terpineol (13.56 \%), DLimonene $(11.50 \%), \gamma$ - terpinene $(10.20 \%)$, isogeraniol $(9.20 \%)$, camphor $(8.95 \%)$, linalool $(6.50 \%)$, cis-piperitol (4.51\%), caryophyllene (4.49\%), $\alpha-$ pinene $(4.30 \%)$, terpinene 4 - acetate (4.25\%), dihydrocarveol (4.20\%), Linalyl acetate $(3.50 \%)$ and 1.8 - cineole $3.50 \%$ ). While, the major components of OTE were cinnamyl alcohol (17.10\%), 
carvacrol $(15.50 \%)$, artemesia triene $(10.50 \%)$, caryophyllene (9.40 \%), Linalool (5.85\%), terpinene 4 - acetate $(5.50 \%)$, thymol $(5.50 \%)$, ocimene $(3.50 \%), 4$ - terpineol $3.20 \%$ ), borneol $(3.10 \%), \quad \beta$-pinene $(3.00 \%)$ and $\gamma-$ terpinen $(2.85 \%)$.

\subsection{Sensory evaluation of fried potato chips}

The results of sensory evaluation of potato chips are given in Table (6). In general, except for the crispiness attribute, the use of OTE or ORE in the frying operation significantly $(\mathrm{P} \leq 0.05)$ improved the sensory scores of fried potato chips. It is also shown that the sensory scores for all attributes examined, decreased significantly from the first day until the third day; however, no sample was unacceptable by panelists. A score of more than 7.5 was considered acceptable on a 10 - point hedonic scale test. The appearance scores of fried potato chips using control oil ranged from 8.3 at first day to 7.8 at the third day, while for fried potato chips using $400 \quad \mathrm{mg} \mathrm{L} \mathrm{L}^{-1}$ concentration on ORE - treated oil, they ranged from 9.4 to 8.5 , and for fried potato chips using $400 \mathrm{mgL}^{-1}$ concentration on OTE - treated oil, they ranged from 9.7 to 8.7. Consequently, the $400 \mathrm{mgL}^{-1}$ of OTE - treated oil in the frying model technique could be considered as the best effective concentration. The decrease in appearance scores was closely related to the deterioration of oils during deep fat frying which caused a darkening of fried potato chips (Che Man and Jaswir, 2000). The darkening of potatoes fried in the oil with OTE or ORE was negligible during deep fat frying and was much lower compared to that for potatoes fried in control oil sample (without OTE or ORE).

Table (6): Effect of ORE and OTE on sensory acceptability of fried potato chips during intermittent deep fat frying.

\begin{tabular}{|c|c|c|c|c|c|c|c|c|c|c|c|c|c|c|c|c|}
\hline \multirow{2}{*}{ Property } & \multirow[b]{2}{*}{$\begin{array}{c}\text { Frying } \\
\text { time (hrs) }\end{array}$} & \multirow[b]{2}{*}{ Control } & \multirow[b]{2}{*}{$\begin{array}{c}\text { BHA } \\
200 \\
\mathrm{mg} / \mathrm{L}\end{array}$} & \multicolumn{6}{|c|}{ Concentration of oleoresin rosemary $(\mathrm{mg} / \mathrm{L})$} & \multicolumn{6}{|c|}{ Concentration of oleoresin thyme $(\mathrm{mg} / \mathrm{L})$} & \multirow[b]{2}{*}{ कิ } \\
\hline & & & & 100 & 200 & 300 & 400 & 500 & 600 & 100 & 200 & 300 & 400 & 500 & 600 & \\
\hline \multirow{3}{*}{ Appearance } & 8 & 8.3 & 8.2 & 8.5 & 9.0 & 9.2 & 9.4 & 8.3 & 7.8 & 9.0 & 9.3 & 9.5 & 9.7 & 8.5 & 8.0 & 0.68 \\
\hline & 16 & 8.0 & 8.0 & 8.1 & 8.5 & 8.8 & 9.0 & 8.0 & 7.5 & 8.5 & 8.9 & 9.1 & 9.4 & 8.3 & 7.8 & 0.71 \\
\hline & 24 & 7.8 & 8.0 & 8.0 & 8.1 & 8.3 & 8.5 & 7.5 & 7.0 & 8.1 & 8.3 & 8.5 & 8.7 & 7.75 & 7.4 & 0.62 \\
\hline \multirow[t]{2}{*}{ L.S. D $5 \%$} & & 0.96 & 10.5 & 0.90 & 0.86 & 0.84 & 0.66 & 0.94 & 0.93 & 0.98 & 0.95 & 1.03 & 1.10 & 1.06 & 0.99 & \\
\hline & 8 & 8.3 & 8.4 & 7.5 & 8.1 & 8.3 & 8.5 & 7.5 & 7.2 & 7.6 & 8.0 & 8.3 & 8.6 & 7.8 & 7.5 & 0.57 \\
\hline \multirow[t]{2}{*}{ Crispiness } & 16 & 7 & 8 & 7.3 & 7 & & & 7 & 7. & & 7 & 8. & 8.3 & & 7.1 & 0.64 \\
\hline & 24 & 7 & 7 & 6.8 & & & 7.6 & 7.0 & 6.9 & 7.3 & 7.4 & 7.6 & 7.8 & 7.3 & 7.0 & 0.62 \\
\hline \multirow{2}{*}{ L.S. D 5\% } & & 1.06 & 1.20 & 0.99 & 0.97 & 0.95 & 0.74 & 1.04 & 1.02 & 1.07 & 1.05 & 1.09 & 1.20 & 1.10 & 1.07 & \\
\hline & 8 & 8.4 & 8.5 & 8.6 & 8.8 & 9.0 & 9.3 & 8.7 & 8.5 & 9.0 & 9.1 & 9.3 & 9.4 & 9.0 & 8.8 & 0.79 \\
\hline \multirow[t]{2}{*}{ Flavor } & 16 & 8.0 & 8.2 & 8.4 & 8.6 & 8.8 & 9.0 & 8.4 & 8.0 & 8.5 & 8.8 & 9.0 & 9.2 & 8.7 & 8.5 & 0.67 \\
\hline & 24 & 7.6 & 7.8 & 7.9 & 8.3 & 8.5 & 8.7 & 8.1 & 7.8 & 8.4 & 8.6 & 8.8 & 9.0 & 8.4 & 8.1 & 0.56 \\
\hline \multirow[t]{2}{*}{ L.S. D $5 \%$} & & 1.07 & 2.05 & 0.93 & 1.05 & 0.80 & 0.60 & 0.86 & 0.87 & 0.93 & 0.90 & 0.97 & 1.05 & 1.00 & 0.94 & \\
\hline & 8 & 8.5 & 8.5 & 8.7 & 9.2 & 9.5 & 9.7 & 8.8 & 8.5 & 8.8 & 9.1 & 9.5 & 9.8 & 9.1 & 8.7 & 0.56 \\
\hline \multirow[t]{2}{*}{ Greasiness } & 16 & 7.9 & 8.0 & 8.4 & 8.8 & 9.0 & 9.3 & 8.5 & 8.1 & 8.6 & 9.0 & 9.4 & 9.5 & 8.7 & 8.4 & 0.63 \\
\hline & 24 & 7.4 & 7.5 & 7.8 & 8.1 & 8.5 & 8.9 & 8.0 & 7.8 & 8.2 & 8.8 & 9.0 & 9.2 & 8.3 & 8.0 & 0.62 \\
\hline L. S. D 5\% & & 0.95 & 1.25 & 0.98 & 0.85 & 0.90 & 0.75 & 0.82 & 0.91 & 0.65 & 0.71 & 0.62 & 0.73 & 0.91 & 0.70 & 0.64 \\
\hline \multirow{3}{*}{$\begin{array}{l}\text { Overall } \\
\text { acceptability }\end{array}$} & 8 & 8.6 & 8.7 & 8.6 & 8.9 & 9.2 & 9.5 & 8.8 & 8.3 & 9.0 & 9.1 & 9.3 & 9.6 & 9.1 & 8.5 & 0.66 \\
\hline & 16 & 8.1 & 8.1 & 8.3 & 8.5 & 8.7 & 9.0 & 8.4 & 8.1 & 8.6 & 8.9 & 9.0 & 9.2 & 8.6 & 8.2 & 0.63 \\
\hline & 24 & 7.8 & 7.9 & 8.0 & 8.0 & 8.4 & 8.75 & 8.0 & 7.4 & 8.0 & 8.3 & 8.5 & 8.8 & 8.0 & 7.6 & 0.60 \\
\hline L. S. D 5\% & & 0.89 & 2.00 & 0.83 & 0.93 & 0.98 & 1.03 & 1.06 & 0.70 & 0.88 & 0.90 & 0.65 & 0.98 & 1.10 & 0.99 & \\
\hline
\end{tabular}

Data in table were presented as mean of three replicates of one sample. The significant difference was evaluated by student's T-test. Using a 10 - point hedonic scale $(1=$ dislike extremely, $6=$ moderate, $10=$ like extremely). Mean of 10 panelists. 
Similarly, the other sensory parameters, either OTE or ORE, added to oils during deep fat frying, significantly $(\mathrm{P} \leq 0.05)$ improved the quality of fried potato chips. The appearance and flavor of fried potato chips are produced mainly by the Millard reaction. OTE and ORE acted antioxidants and seemed not only to reduce oxidation but also to block, indirectly, the Millard reaction. This resulted in a reduction of the dark color of chips during frying. Darkening during frying is observed mainly due to the reaction between the free sugars and amino acids. The typical flavor of fried potato chips is due to compounds formed via the Millard reaction. During the progressive frying of chips, more and more members of the sensory panel could distinguish a difference in flavor between the fried potato chips in sunflower oil with and/or without antioxidants. Fried potato chips in oil without OTE or ORE had a low overall acceptability contributed by the oxidation of the absorbed oil in chips. Panelists preferred the chips fried in oil treated with OTE or ORE. Acceptable sensory characteristics of potatoes chips were observed when OTE and/or ORE were added to the frying medium (Table 6). Indeed, increasing the frying time to $24 \mathrm{hrs}$. markedly decreased the sensory attributes scores of fried potato chips in all technique model systems of sunflower oil. This may be attributed to the fact that the composition of unsaturated fatty acids changes with subsequent heating and cooling, which comprise TPCs, TBA, IP accompany or parallel to chemical analysis results of frying oil, as reported by Abd-El-Ghany (2006), El-Naggar
(2007) and Morales et al. (2014). In the present time, there is trend to use the natural extracts as antioxidants, led to retarding the oxidation process during thermal treatments of edible oils. The results could be concluded that addition of OTE and/or ORE to oils kept its characteristics from being deteriorated during frying or heating model technique as IP, TPCs and TBA of oil were concerned. The addition of antioxidants to oil is one of the most efficient ways to prevent oxidation of lipids. Phenolic antioxidants such as Butylated Hydroxy Anisole (BHA), Butylated Hydroxy Toluene (BHT), Tertiary Butylated Hydroxy Quinone (TBHQ) and propyl Gallate (PG), are used as synthetical antioxidants in foodstuff against rancidity. These synthetic substances have been shown to cause several diseases, i.e. enlarge the liver, hyperplasia of the forestomach and growth retardation (Ullah et al., 2003). Natural antioxidants are found in the medicine plants, i.e. thyme and rosemary. Natural antioxidants are believed to be safer than synthetic substance. During the simulated frying or heating model system, the OTE or ORE may act as an antioxidant taking part in the chain radical oxidation, as well as simultaneously inhibiting the pure thermal processes occurring in sunflower oil. The results illustrate that the addition of the OTE or ORE up to $400 \mathrm{mgL}^{-1}$ causes a slower increase in both of TPCs, TBA and acrylamide content during treatment at $175^{\circ} \mathrm{C}$ in comparison to the increase of TPCs, TBA and acrylamide content in the control samples, findings demonstrate that the OTE on both IP, TPCs, TBA and acrylamide content is 
more pronounced up to $400 \mathrm{mgL}^{-1}$. Hence, addition of OTE or ORE to sunflower oil leads to a decrease in the thermal changes in the oil occurring during its high temperature treatment. Under the conditions simulated frying or heating model system, OTE inhibits the oxidative processes more strongly than the ORE or BHA. The lower values of TPCs, TBA and acrylamide content shown by the samples using either OTE or ORE compared to the values of control samples could be caused by the ability of the antioxidant to retard the deterioration of the oil during frying or heating model system. Additionally, results demonstrate that the heating model system causes a slower increase in acrylamide content during treatment at $175^{\circ} \mathrm{C}$ in comparison to frying model system. Since acrylamide forms from reducing sugars and asparagine as a consequence of the Millard reaction when foods are subjected to high temperatures (Mesias et al., 2016). Besides, acrylamide forms from oil deterioration products under heating model technique. These results strongly supported our hypothesis in that the heating model technique might increase the formation of acrylamide during intermittent heating process. (pathways based on acrolein intermediates, because acrolein has structural similarities to acrylamide. Acrolein can be formed by both of hydrolysis and oxidantion of triacylglycerol (Zyzak et al., 2003). Acrylamide is produced mainly in the Millard reaction (Nira et al., 2017). The conversion of free non-protonated amine to protonated amine is easily obtained by lowering PH of the system (Jung et al., 2003). The first step of acrylamide formation in Millard reaction is formation of Schiff base via nucleophilic addition of $\alpha$ - amino group of the asparagine to the partially positive carbonyl carbon of dicarbonyl compound, if the nucleophilic free non-protonated amine $\left(-\mathrm{NH}_{2}\right)$ is converted to non-nucleophilic protonated amine $\left(-\mathrm{NH}_{3}^{+}\right)$, the nuclerophilic attack would be effectively blocked (Gramza et al., 2006; Jung et al., 2003; Mesias et al., 2016; Mottram et al., 2002). Hence, addition of antioxidants may block the oxidation of 3 - amino pro-pionamide by converted the free non-protonated amine to protonated amine in foods. Such phenomenon may be due to their antioxidants property and thermo stability. Zhang et al. (2008) demonstrated that the antioxidant effect of green tea polyphenol extracts assessed by the $\beta-$ carotene bleaching method weakens with the increase of heating time. Meanwhile, poor thermo stability of tea polyphenols in a high heating temperature or long heating time reduces their ability to exert their antioxidants activity (Morales et al., 2014; Nira et al., 2017). As Lalas and Dourtoglou (2003) and Wang et al. (2013) stated the level of protection against oxidation is different compounds and synergistic effects between them. The effectiveness of OTE and ORE as lipid antioxidants has been attributed mainly to their ability to remain stable during deep fat frying (Che Man and Tan, 1999). OTE or ORE contain phenolic antioxidants that react with lipid or hydroxyl radical and convert them into stable products. The major antioxidants in these extracts may be protected by other substances, flavonoids, found in smaller amounts, which provide thermal stability 
and enhanced antioxidative activity (Che Man and Jaswir, 2000; El-Naggar, 2010; Morales et al., 2014; Nira et al., 2017; Ullah et al., 2003). Also, Morales et al. (2014) reported that commercial rosemary extracts contain phenolic primary antioxidants which react with oil or hydroxyl radicals and convert them into stable products. Moreover, Ullah et al. (2003) reported that rosemary extracts may chelate metal ions, such as Fe resulting in a reduce rate of formation of activated oxygen. In this respect, ElNaggar (2010) and Nira et al. (2017), they found that both of rosemary and sage extracts were as effective in reducing TBA as the synthetic antioxidants, BHA. From the healthy point of view the maximum permissible level and the healthy hazards due to dietary intake of acrylamide in processed foods are varied from country to another. The World Health Organization (2005) estimates a daily intake of dietary acrylamide in the range of $0.3-2.0 \mathrm{mg} / \mathrm{kg}$ body weight/day for the general population. Thereafter, the potato chips samples should be added oleoresin thyme or rosemary extracts up to $400 \mathrm{mgL}^{-1}$ of oil, as the inhibitory effect on the thermal deterioration of oil, consequently acrylamide formation level in potato chips. Conclusion; It could be observed that the using OTE and/ or ORE in sunflower oil during intermittent deep fat frying improve its frying characteristics and reduce the acrylamide formation level. Based on these results can be recommended for use thyme or rosemary extracts during intermittent deep fat frying.

\section{References}

Abd-El-Ghany, M. E. (2006), Studies on Egyptian ben (Moringa) seeds as non-conventional source of edible oil, Ph.D. thesis, Faculty of Agriculture, Al-Azhar University, Egypt.

AOAC (2000), Official Method of Analysis Association of Official Analytical Chemistry, International $17^{\text {th }}$ ed., Washington D.C., USA.

Bandoniene, D., Venskutonis, P. R., Gruzdiene, D. and Murkovic, $M$. (2002), "Antioxidative activity of sage (Salvia officinalis L.), savory (Saturejahortensis L.) and borage (Borago officina lis L.) extracts in rapeseed oil", European Journal Lipid Sciences Technology, Vol. 104, pp. 286-292.

Che Man, Y. B and Tan, C. P. (1999), "Effects of natural and synthetic antioxidants on changes in refined, bleached, and deodorized palm olein during deep fat frying of potato chips", Journal of American Oil Chemists Society, Vol. 76 No. 3, pp. 331-339.

Che Man, Y. B. and Jaswir, I. (2000), "Effect of rosemary and sage extracts on frying performance of refined, bleached and deodorized (RBD) palm olein during deep-fat frying", Food Chemistry, Vol. 69, pp. 301-307. 
Delgado, R. M., Luna-Barcenas, G., Arambula-Villa, G., Azuara, E., Lopez-Perea, P. and Salazar, R. (2014), "Effect of water activity in tortilla and its relationship on the acrylamide content after frying", Journal of Food Engineering, Vol. 143 , pp. $1-7$.

EFSA (European Food Safety Authority), 2015, "Scientific opinion on acrylamide in food", EFSA Journal, Vol. 13 No. 6, ID 4104.

El-Beltagy, A. E. and Mubarak A. E. (2005), "Reducing of acrylamide formation in fried potatoes", Minufiya Journal Agricultural Research, Vol. 30 No. 6, pp. 17571766.

El-Naggar, E. A. (2010), "Evaluation of some quality attributes and acrylamide content of some edible oils during deep fat frying of potato chips", Egypt Journal of Applied Sciences, Vol. 25 No 10B, pp. 530545.

El-Naggar, E. E. (2007), Effect of different heat treatments on the physical, chemical and biological characteristics of some edible oils, Ph.D. Thesis, Faculty of Agriculture, Al-Azhar University, Egypt.

El-Saied, M. H., Sharaf, A. M., AbulFadl, M. M. and El-Badry, N. (2008), "Reduction of acrylamide formation in fried potato strips by different pre-frying treatments", World Journal of Dairy and Food
Science, Vol. 3 No.1, pp. 17-24.

Esposito, F., Nardone, A., Fasano, E., Triassi, M. and Cirilloo, T. (2017), "Determination of acrylamide levels in potato crisps and other snacks and exposure risk assessment through a Margin of Exposure approach", Food and Chemical Toxicology, Vol. 108, pp. 249-256.

FAO/WHO (2002), Consultation on the health implication of acrylamide in food, Summary Report, Geneva, Switzerland.

Gertz, C. and Klostermann, S. (2002), "Analysis of acrylamide and mechanisms of its formation in deep fried products", European Journal Lipid Science Technology, Vol. 104, pp. 762- 771 .

Gramza, A., Khokhar, S., Yoko, S., Swiglo, A. and Hes, M. (2006), "Antioxidant activity of tea extracts in lipids and correlation with polyphenol content", European Journal Lipid Science Technology, Vol. 108 No. 4, pp. 351-362.

Ihekoronye, A. I. and Ngoddy, P. O. (1985), Integrated food science and technology for the tropics, Macmillan Publishers, London, England, pp. 310-316.

Jaswir, I., Che Man, Y. B. and Kitts, D. (2000), "Synergistic effects of rosemary, sage and citric acid on fatty acid retention of palm olein during deep fat frying", Journal 
American Oil Chemists Society, Vol. 77 No. 5, pp. 527-533.

Jung, M. Y., Choi, D. S. and Ju, J. W. (2003), "A novel technique for limitation of acrylamide formation in fried and baked corn chips and in French fries", Journal of Food Science, Vol. 68 No. 4, pp. 12871290.

Lalas, S. and Dourtoglou, V. (2003), "Use of rosemary extract in preventing oxidation during deep fat frying of potato chips", Journal American Oil Chemists Society, Vol. 80 No. 6, pp. 479-583.

Lee, J., Lee, S., Lee, H., Park, K. and Choe, E. (2002), "Spinach (Sponacia oleracea) powder as a natural foodgrade antioxidant in deep fat fried product", Journal Agriculture of Food Chemistry, Vol. 50, pp. 56645669.

Lindsay, R. (2002), Generalized potential origins of acrylamide in foods, Workshop on Food Research Institute (FRI) Acrylamide project, Chicago, USA.

Meghavarnam, A. K. and Janakiraman, S. (2017), "Evaluation of acrylamide reduction potential of Lasparaginase from Fusarium culmorum (ASP - 87) in starchy products", LWT- Food Science and Technology, Vol. 89, pp. 32-37.

Mesias, M., Holgado, F., Marqyez-Ruiz, G. and Morales, F. J. (2016),
"Impact of the characteristics of fresh potatoes available in retail on exposure to acrylamide: case study for French fries", Food Control, Vol. 73B, pp. 1407-1414.

Michalak, J.; CukskaE;.KujawskaMand Nowak F. (2017). "Effect of different home - cooking methods on acrylamide formation in preprepared croquettes". Journal of Food Composition and Analysis, (56): pp.134 - 139.

Morales, G., Jimenez, M., Garcia, O., Mendoza, M. R. and Beristain, G. I. (2014), "Effect of natural extracts on the formation of acrylamide on fried potatoes", LWT-Food Science and Technology, Vol. 58 No. 2, pp. 587593.

Mottram, D. S., Wedzicha, B. L., Dodson, A. T. (2002), "Acrylamide is formed in Millard reaction", Nature, Vol. 419 No. 3, pp. 448449.

Nira, M., Powers, S. J., Elmore, J. S., Dodson, A., Briddon, A., Mottram, D. S. and Halford, N. G. (2017), "Acrylamide forming potential of potatoes grown at different locations, and the ratio of free asparagine to reducing sugars at which free asparagine becomes a limiting factor for acrylamide formation", Food Chemistry, Vol. 220, pp. 76-86.

Ozkan, G., Sagdic, O., Gokturk, R. S., Unal, O. and Albayrak, S. (2010), 
"Study on chemical composition and biological activities of essential oil and extract from Salvia pisidica", LWT-Food Science and Technology, Vol. 43, pp. 186-190.

SAS (2000), SAS User's Guide Statistical Analysis System, SAS Institute, North Carolina, USA.

Singh, S. and Tyagi, V. K. (2001), "Deep fat frying of foods. Its significance on nutrition and health", Journal of Food Science and Technology, Vol. 38 No. 6, pp. 545-552.

Ullah, J., Hamayoun, M., Ahmad, T., Ayub, M. and Zafarulla M. (2003), "Effect of light, natural and synthetic antioxidants on stability of edible oil and fats", Asian Journal of plant Sciences, Vol. 2 No. 17, pp. 1192-1194.

FDA (United States Food and Drug Administration), (2002), Exploratory data on acrylamide in foods, U.S. FDA, CFSAN/Office of Plant \& Dairy Foods, USA.

Wang, H., Feng, F., Guo, Y., Shuang, S. and Choi, M. F. (2013), "HPLC-UV quantitative analysis of acrylamide in bakes and deep-fried Chinese foods", Journal of Food Composition and Analysis, Vol. 31, pp. 7-11.

World Health Organization, (2005), Summary Report of the Sixty Fourth Meeting of the Joint FAO/WHO Expert Committee on
Food Additive (JECFA), The ILSI Press International Life Sciences Institute, Rome, Italy, pp. 1-47.

Xu, X. (1999), "A modified very - fry quick test for measuring total polar compounds in deep fat frying oils", Journal American Oil Chemists Society, Vol. 75 No. 9, pp. 10871089.

Yanishleva, N. V., Marinova, E. M., Marekov, I. N. and Gordon, M. H. (1997), "Effect of an ethanol extract from summer savory (Satureja hortensis L.) on the stability of sunflower oil at frying temperature", Journal of the Science of Food and Agriculture, Vol. 74, pp. 524-530.

Youssef, M. M., Abou-Gharbia, H. A. and Abou-Bakr, H. A. (2004), "Acrylamide in food an overview", Alexandria Journal of Food Science and Technology, Vol. 1 No. 1, pp. $1-22$.

Zhang, Q., Saleh, A. S. M., Chen, J. and Shen, Q. (2012), "Chemical alteration taken place during deep fat frying based on certain reaction products", Chemistry and physics of lipids, Vol. 165, pp. 662-681.

Zhang, Y., Ying, T. and Zhang, Y. (2008), "Reduction of acrylamide and its kinetics by addition of antioxidant of bamboo leaves (AOB) and extract of green tea (EGT) in asparagine-glucose microwave heating system", Journal of Food Science, Vol. 73 No. 2, pp. 60-66. 
Zyzak, D. V., Sanders, R. A., Stojanovic, M., Tallmadge, D., loye, B., Ewald, D., Gruber, D., Morsch, T. R., Rizzi, G. and Villagran, M. D. (2003), "Acrylamide formation mechanism in heated foods", Journal Agriculture of Food Chemistry, Vol. 51, pp. 4782-4787. 